\title{
Modeling the behavior of Vegetation Indices in the salt dome of Korsia in North-East of Darab, Fars, Iran
}

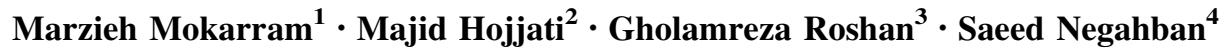

Received: 29 July 2015/Accepted: 17 August 2015/Published online: 11 September 2015

(C) Springer International Publishing Switzerland 2015

\begin{abstract}
The use of remote sensing for rapid and accurate evaluation of phenomena, specially land covers is very important. In this study, for modeling and estimated of salt dome was used visible atmospherically resistant index (VARI), difference vegetation index (DVI), enhanced vegetation index $(\mathrm{EVI})$, green difference vegetation index (GDVI), normalized difference vegetation index (NDVI), optimized soil adjusted vegetation index (OSAVI), soil adjusted vegetation index (SAVI), infrared percentage vegetation index (IPVI) by Landsat $8 \mathrm{ETM}+$ bands vegetation in the salt dome of Korsia of Darab plain, Iran in 2015 years. By software ENVI preprocessing, processing, geometric and atmospheric corrections were performed, and then vegetation index for the study area was calculated. Also ArcGIS 10.2 software for mapping of area vegetation was applied. Then relationship between Vegetation Indices and salt dome of Korsia were determined. The results show that the value of indices were high in the agriculture field for VARI, DVI, GDVI and IPVI and low value for other indices. Also the results show that cannot used IPVI and
\end{abstract}

Gholamreza Roshan

ghr.roshan@gu.ac.ir; r.rowshan@yahoo.com

Marzieh Mokarram

m.mokarram@shirazu.ac.ir

Saeed Negahban

snegahban@shirazu.ac.ir

1 Department of Range and Watershed Management, College of Agriculture and Natural Resources of Darab, Shiraz University, Shiraz, Iran

2 Department of Remote Sensing and GIS, College of Geography, University of Tehran, Tehran, Iran

3 Department of Geography, Golestan University, Gorgan, Iran

4 Department of Geography, Shiraz University, Shiraz, Iran
OSAVI for determination of soil salinity. DVI and SAVI close to 0.1 and 0.2 is represent soil salinity respectively. Also soil salinity have EVI and GDVI close to 0.14 . Finally VARI and NDVI have value of lower that 0 in soil salinity. The comparison of vegetation indices show that change values were same for SAVI, EVI, GDVI and DVI in salt dome. Finally the results show that EVI, GDVI, OSAVI and SAVI are suitable for prediction and modeling of salt dome in the study area.

Keywords Landsat 8 ETM+ + Remote sensing · Vegetation index $\cdot$ Salt dome of Korsia

\section{Introduction}

Facing the risk of soil salinization worldwide, there has been a growing interest in identifying rapid and inexpensive tools for soil salinity assessment (Metternicht and Zinck 2003). Remote sensing is a technique that uses special tools without physical contact with the target for gaining information about the purpose (Seyhan 2004). Remote sensing data, because of its features such as multitemporal, multi-spectral, functionality and good spatial resolution and radiometric diverse, broad and integrated vision, able to separate the different farming conditions and phenomena such as surface, and patterns of time and where are cultivated (Abdollah Zadeh and Nasiri 2008, Yospin et al. 2015, Ghanghermeh et al. 2015).

Regular and careful observation of forest and losses of nitrogen deficiencies, water stress or insects could be facilitated by the development of adequate management strategies (Tillack et al. 2014). Remote sensing techniques are cost-effective method for quantitative estimates of biomass at regional and local scales. The emergence of 
hyperspectral sensors, which offer an approximately contiguous spectrum, has opened a new perspective to quantify and assess the biophysical properties including biomass ( $\mathrm{Fu}$ et al. 2014). As a result of using non-destructive spectral reflectance data obtained from satellite data, spectrometers, etc. study of the agricultural parameters is facilitate and accelerate (Gnyp et al. 2014). Li et al. (2015) stated that the use of remote sensing techniques and the application of GIS (Geographic Information System) are increasingly easier to measure vegetation cities.

Vegetation indices is one of the enhancement methods of information extraction in satellite images that have been developed and used for evaluating the biophysical and biochemical parameters of the plant. The indices for ease of use are one of the most common techniques of remote sensing for estimating such parameters (Bannari et al. 2006). Vegetation index compared with measured vegetation has benefits include reduced time, frequency data and saving on the cost and labor least.

Many studies on the use of remote sensing techniques and vegetation indices in agriculture and natural resources are done. Arzani et al. (2009) using indicators SAVI (Soiladjusted Vegetation Index), MSAVI (Modified Soil Adjusted Vegetation Index) and PVI have proposed to estimate the crown of Vegetation. In northern China, Bao et al. (2009) predicted winter wheat biomass and Ren et al. (2008) monitored winter wheat yield using data from Modis, and Koppe et al. (2012) estimated estimated winter wheat biomass using Hyperion data. Vegetation index NDVI (Normalized Difference Vegetation Index), NDVIRE (Red Edg NDVI), msR-RE (Modified Red Edge Simple Ratio) and Curvature demonstrated that the spatial and temporal variations in leaf area index (LAI) as well can be estimate (Tillack et al. 2014). Ren et al. (2011) showed that the linear model based on NDVI $(862,693 \mathrm{~nm})$ relative to the index, SAVI is composed of 887 and $685 \mathrm{~nm}$ bands had a better estimates of green biomass of the desert steppe. Ji et al. (2012) also stated that remote sensing can be a good alternative for mapping ground biomass. Baihua and Burgher (2015) stated that the vegetation index NDVI is a good indicator to identify and assess long-term changes in the areas of vegetation.

Zhang et al. (2011) used hyperspectral vegetation indices as a proxy to monitor soil salinity. By combining the most sensitive bands in a SAVI form, they finally proposed four soil adjusted salinity indices (SASIs) for all species. Satisfactory relationships were observed between ECe and four SASIs for all species, with largely improved $\mathrm{R}^{2}$ values ranging from 0.50 to 0.58 . Moreover, the use of vegetation reflectance as an indirect indicator can avoid limitations associated with the direct use of soil reflectance.
Allbed et al. 2014 determined relationship between soil salinity and vegetation indices derived from IKONOS high-spatial resolution imageries. The results show that among the investigated indices, the Soil-Adjusted Vegetation Index (SAVI), Normalized Differential Salinity Index (NDSI) and Salinity Index (SI-T) yielded the best results for assessing the soil salinity of cultivated lands with dense and uniform vegetation.

These limitations include the influences of complicated soil context (e.g. moisture, surface roughness, and organic matter) (Ben-Dor et al. 1999), weak diagnostic features under poor salt crystallization (salt content $<10-15 \%$ ) (Mougenot et al. 1993), and spectral confusions with the presence of vegetation itself and other surface features (Metternicht and Zinck 2003; Zhang et al. 2011).

Modeling vegetation was used Gabriel et al. (2015) parameterized FireBGCv2 to identify the effects of different levels of ignition suppression on landscape-level patterns of vegetation and successional dynamics in subalpine Tasmania. The results show that because the distribution of vegetation types was unstable temporally and across stochastic replicates, present distributions may be a legacy of previous climate, Aboriginal fire management, or both.

The study area for modeling and understanding the behavior of Vegetation Indices in the salt dome was used satellite image. For determination of relationship between salt dome of Korsia of Darab plain used VARI, DVI, EVI, GDVI, NDVI, OSAVI, SAVI and IPVI based on Landsat 8 $\mathrm{ETM}+$ in 2015 years.

\section{Materials and methods}

\section{Case study}

The case areas were selected from ten different locations in salt dome of Korsia- Darab plain. The study area is located at $28^{\circ} 28^{\prime} 46^{\prime \prime} \mathrm{N}$ and $54^{\circ} 23^{\prime} 40^{\prime \prime} \mathrm{E}$, with area of $1083 \mathrm{~km}^{2}$. The locations of the case areas are shown in Fig. 1.

In this study to calculate the indices VARI, DVI, EVI, GDVI, NDVI, OSAVI, SAVI and IPVI have been used of bands $1,2,3,4,5$ and 7 Landsat $8 \mathrm{ETM}+$ sensor, 2015 years. Spectral characteristics of ETM+ bands are shown in Table 1.

First, using ENVI v.5 preprocessing like geometric and atmospheric corrections were performed, and then vegetation indices for the study area was calculated. ArcGIS10.2 software for mapping of area vegetation was used. Then indexes compared with land use map in order to determine best index for estimate vegetation in study area. 
Fig. 1 Position of the study area

Table 1 Spectral characteristics of Landsat 8 $\mathrm{ETM}+($ NASA 2013)

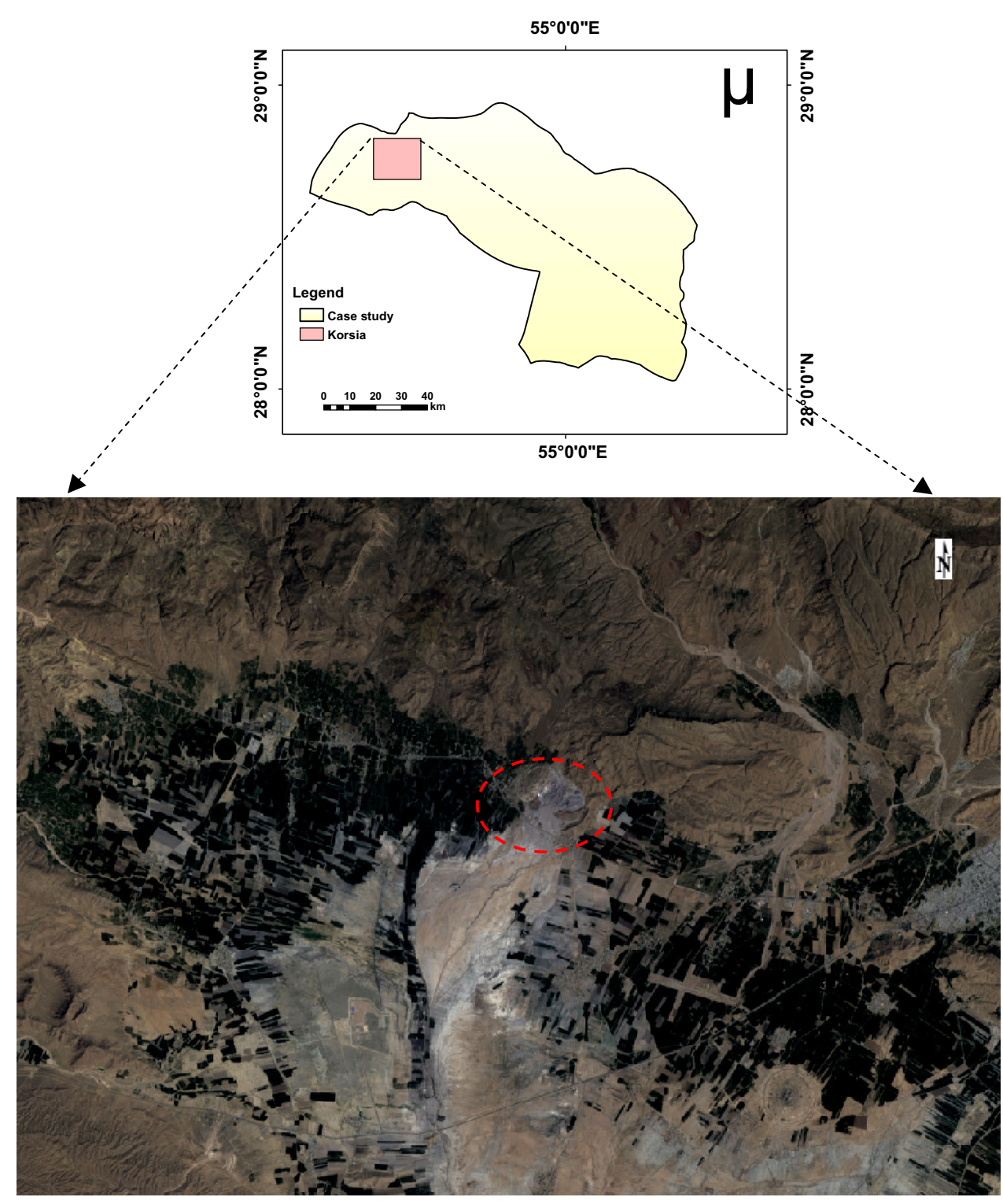

\begin{tabular}{lll}
\hline Spectral band & Wavelength $(\mu \mathrm{m})$ & Resolution $(\mathrm{m})$ \\
\hline Band 1-coastal/aerosol & $0.433-0.453$ & 30 \\
Band 2-blue & $0.450-0.515$ & 30 \\
Band 3-green & $0.525-0.600$ & 30 \\
Band 4-red & $0.630-0.680$ & 30 \\
Band 5-near infrared & $0.845-0.885$ & 30 \\
Band 6- short wavelength infrared & $1.560-1.660$ & 30 \\
Band 7-short wavelength infrared & $2.100-2.300$ & 30 \\
Band 8-panchromatic & $0.500-0.680$ & 15 \\
Band 9-cirrus & $1.360-1.390$ & 30 \\
\hline
\end{tabular}




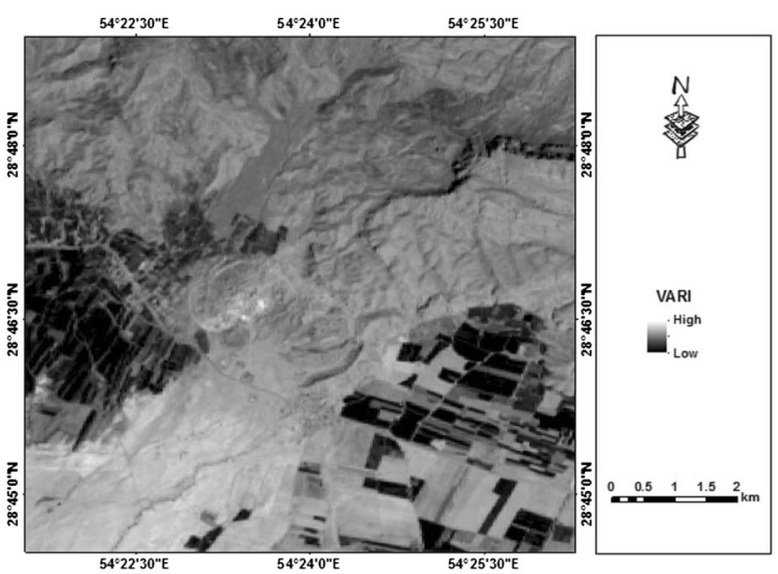

(a)

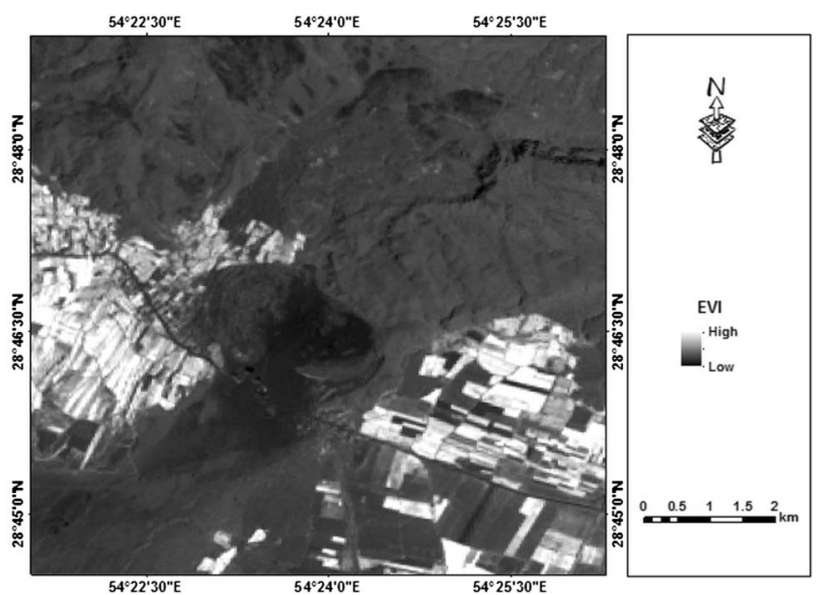

(c)

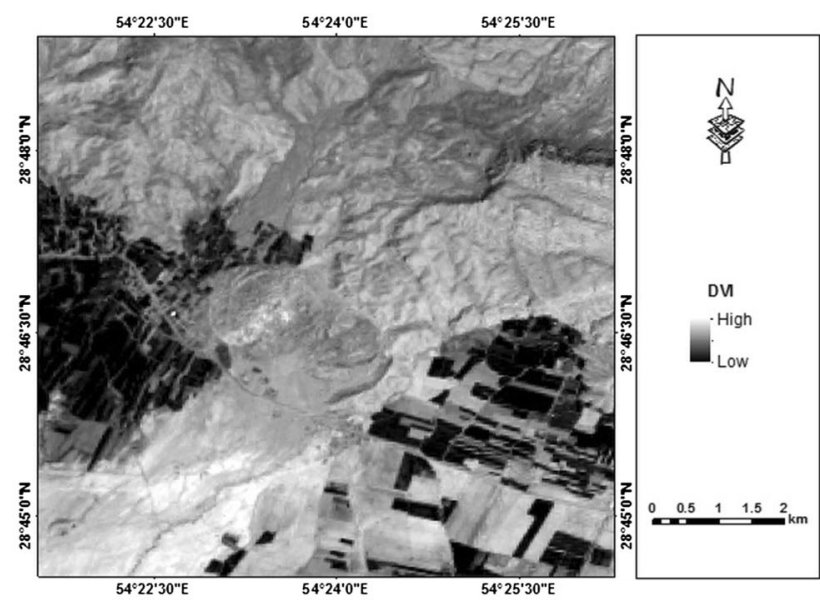

(b)

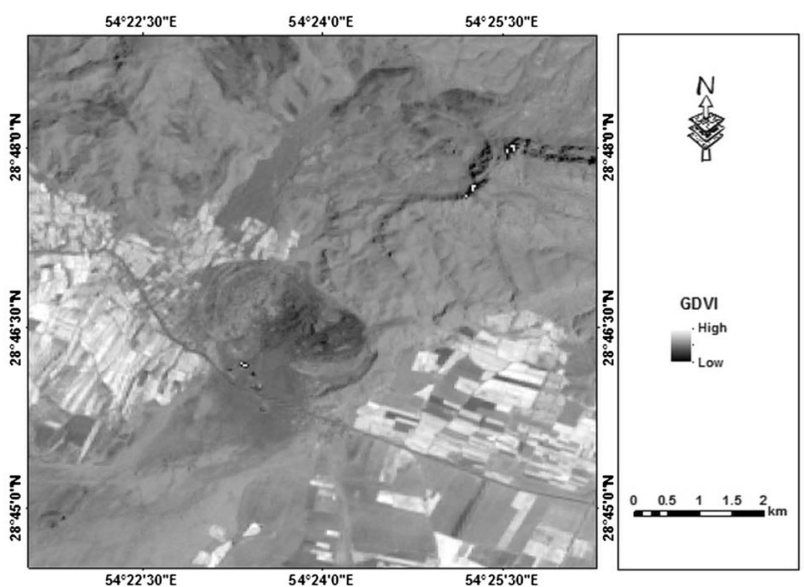

(d)

Fig. 2 Vegetation indices of the study area. The value of indices were high in the agriculture field for VARI, DVI, GDVI and IPVI and low for other indices. a VARI, b DVI, c EVI, d GDVI, e IPVI, f NDVI, g OSAVI, h SAVI

\section{Vegetation indices}

Visible atmospherically resistant index (VARI)

This index is based on the ARVI and is used to estimate the fraction of vegetation in a scene with low sensitivity to atmospheric effects (Gitelson et al. 2002)

$V A R I=\frac{\text { Green }- \text { Red }}{\text { Green }+ \text { Red }- \text { Blue }}$

\section{Difference vegetation index (DVI)}

This index distinguishes between soil and vegetation, but it does not account for the difference between reflectance and radiance caused by atmospheric effects or shadows (Tucker 1979).

$D V I=N I R-R e d$

\section{Enhanced vegetation index (EVI)}

This index was developed as a standard MODIS product to improve the NDVI by optimizing the vegetation signal in LAI regions. It uses the blue reflectance region to correct for soil background signals and to reduce atmospheric influences, including aerosol scattering. It is most useful in LAI regions where the NDVI may saturate (Huete, et al. 2002).

$E V I=2.5 * \frac{(\text { NIR }- \text { Red })}{(N I R+6 * \text { Red }-7.5 * \text { Blue }+1)}$

The value of this index ranges from -1 to 1 .

\section{Green difference vegetation index (GDVI)}

This index was originally designed with color-infrared photography to predict nitrogren requirements for corn (Sripada et al. 2006). 


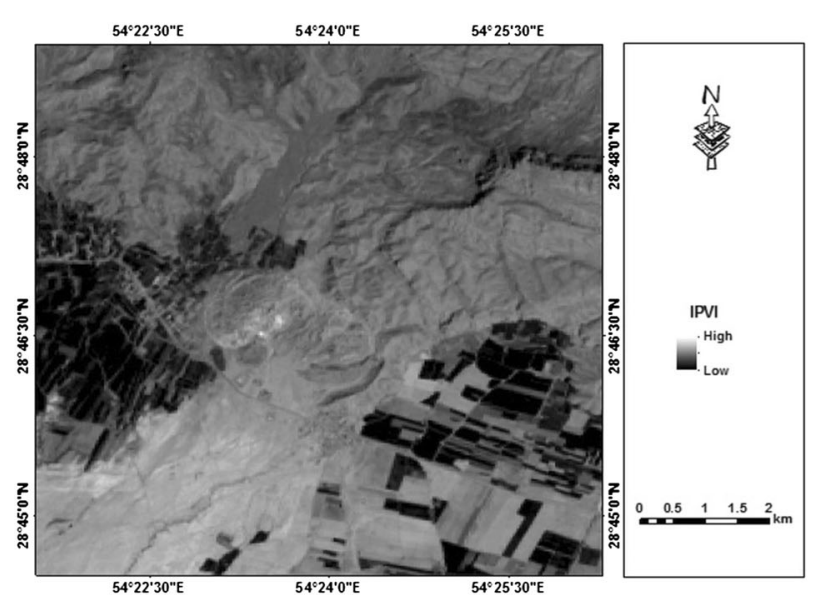

(e)
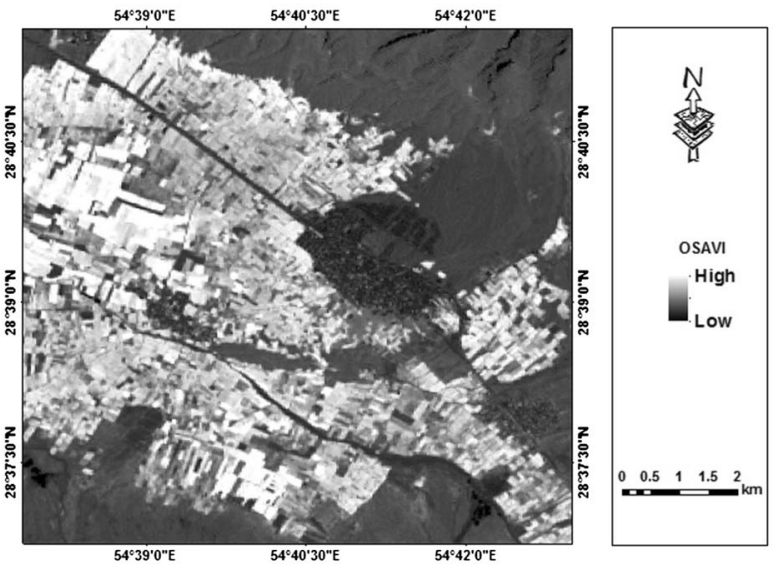

(g)

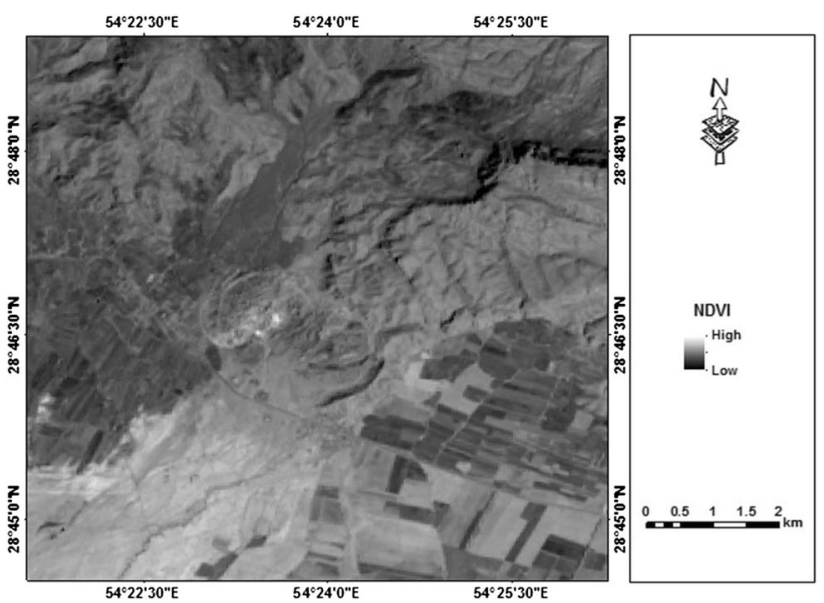

(f)

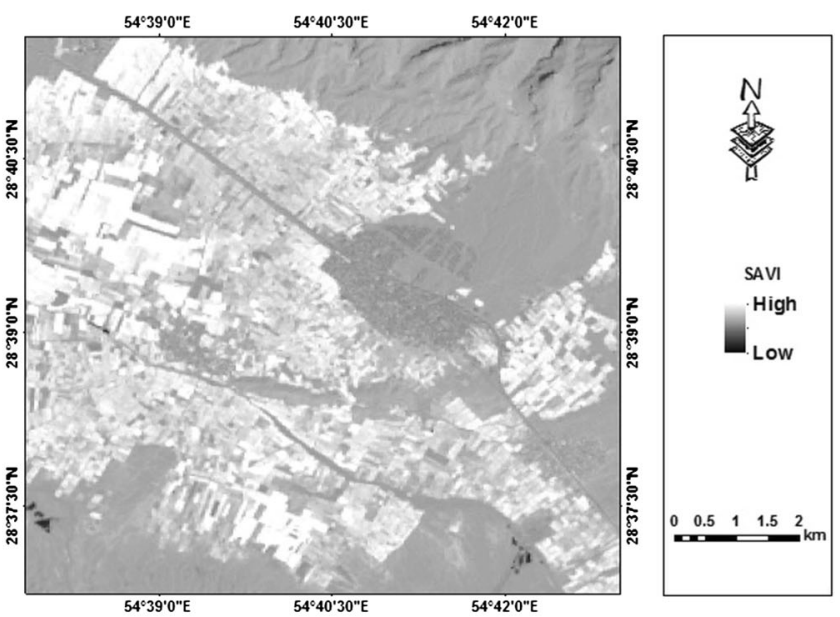

(h)

Fig. 2 continued

$G D V I=N I R-$ Green

\section{Normalized difference vegetation index (NDVI)}

This index is a measure of healthy, green vegetation. The combination of its normalized difference formulation and use of the highest absorption and reflectance regions of chlorophyll make it robust over a wide range of conditions. It can, however, saturate in dense vegetation conditions when LAI becomes high (Rouse et al. 1973).

$N D V I=\frac{(N I R-R e d)}{(N I R+R e d)}$

The value of this index ranges from -1 to 1 . The common range for green vegetation is $0.2-0.8$.
Optimized soil adjusted vegetation index (OSAVI)

This index is based on the soil adjusted vegetation index (SAVI). It uses a standard value of 0.16 for the canopy background adjustment factor. Rondeaux et al. (1996) determined that this value provides greater soil variation than SAVI for low vegetation cover, while demonstrating increased sensitivity to vegetation cover greater than $50 \%$. This index is best used in areas with relatively sparse vegetation where soil is visible through the canopy.

$O S A V I=\frac{1.5 *(N I R-R e d)}{(N I R+R e d+0.16)}$

\section{Soil adjusted vegetation index (SAVI)}

This index is similar to NDVI, but it suppresses the effects of soil pixels. It uses a canopy background adjustment 


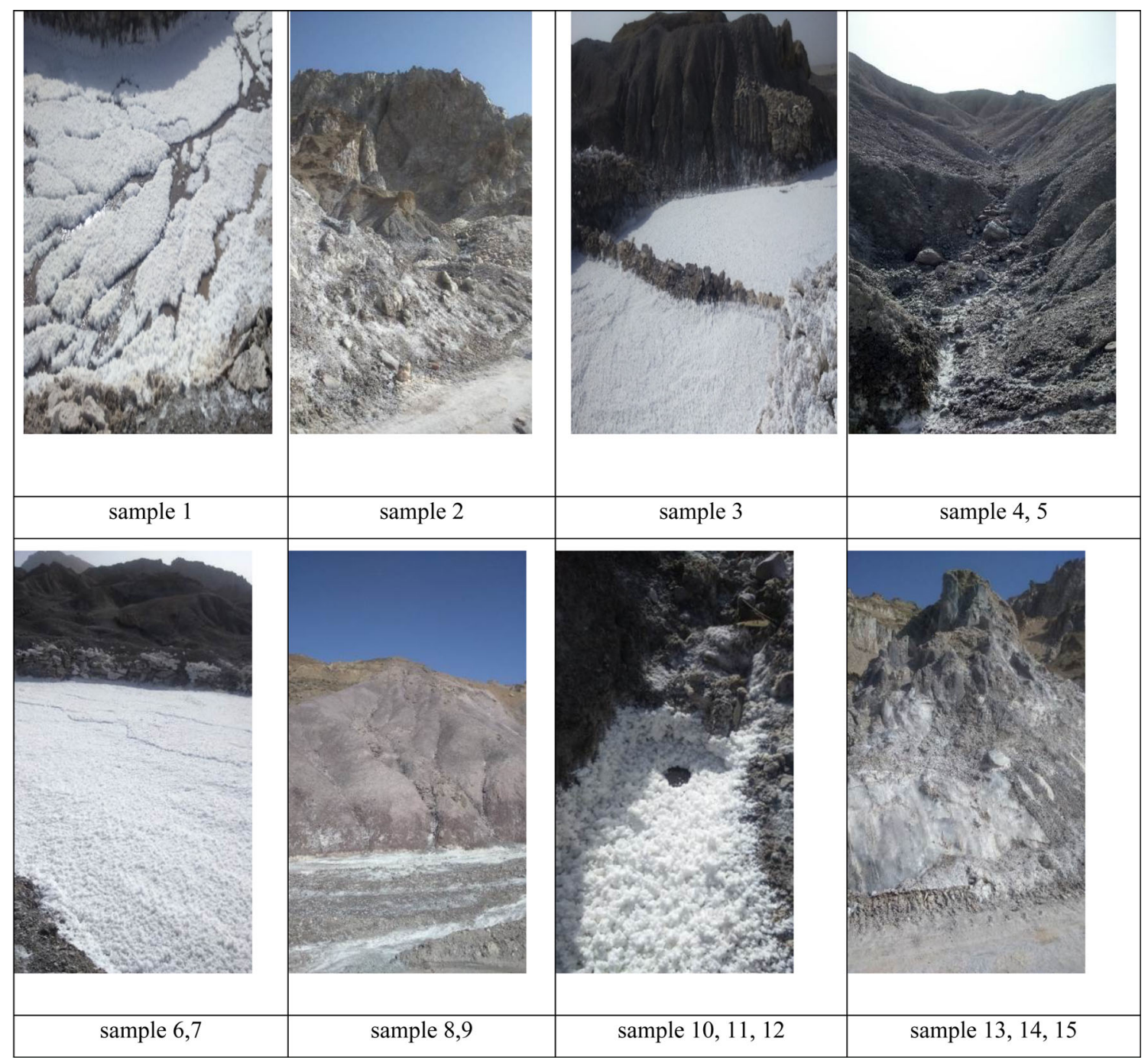

Fig. 3 Position of 15 samples in the ground from salt dome of Korsia-Darab plain. In each of the samples, the salt could be seen in different forms

factor, $L$, which is a function of vegetation density and often requires prior knowledge of vegetation amounts. Huete (1988) suggests an optimal value of $L=0.5$ to account for first-order soil background variations. This index is best used in areas with relatively sparse vegetation where soil is visible through the canopy.

$S A V I=\frac{1.5 *(N I R-R e d)}{(N I R+R e d+0.5)}$

\section{Infrared percentage vegetation index (IPVI)}

This index is functionally the same as NDVI, but it is computationally faster. Values range from 0 to 1 (Crippen 1990).

$I P V I=\frac{N I R}{N I R+R e d}$

\section{Results and discussion}

The results of the vegetation indices (VARI, DVI, EVI, GDVI, NDVI, OSAVI, SAVI and IPVI) show in the Fig. 2. According to Fig. 2, value of indices were high in the agriculture field for VARI, DVI, GDVI and IPVI and low for other indices. Vegetation is low in the salt land. So salt land seen white color in satellite images (Prost 2013). From between vegetation indices, EVI, GDVI, OSAVI and SAVI is show salt dome to black color (high value). While other vegetation indices show salt land to white color (high value). So EVI, GDVI, OSAVI and SAVI are suitable for prediction and modeling of salt dome in the study area.

In order to determination of the best vegetation index used 15 sample points. The position of 15 sample points show in Fig. 3. The relationship between each of vegetation indices and sample points show in Fig. 4. 


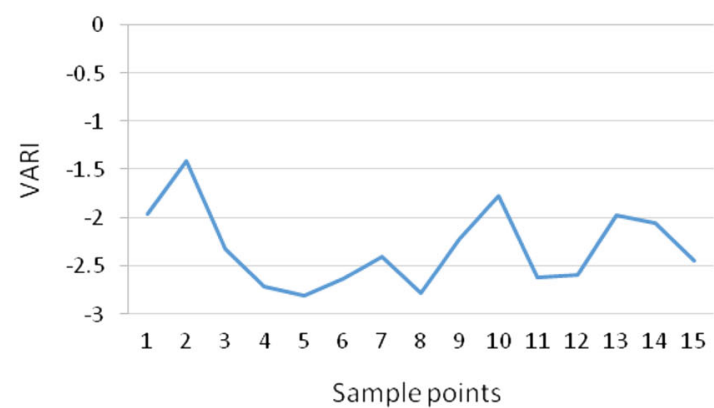

(a)

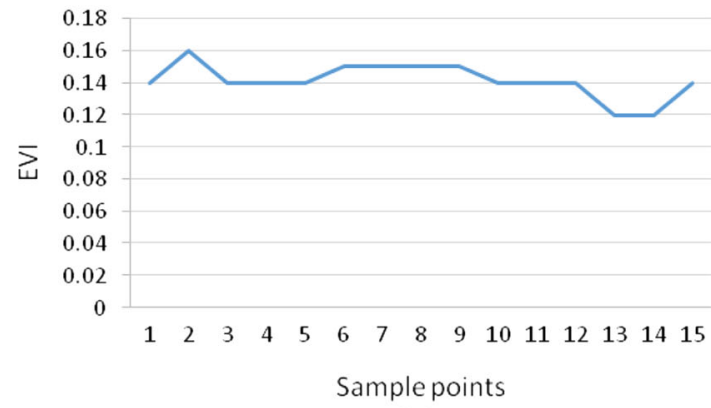

(c)

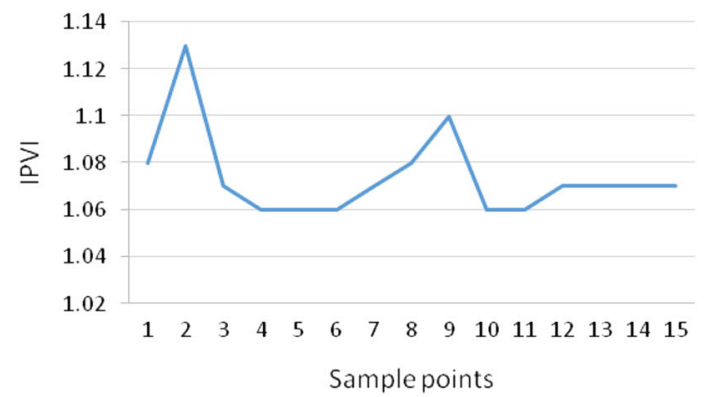

(e)

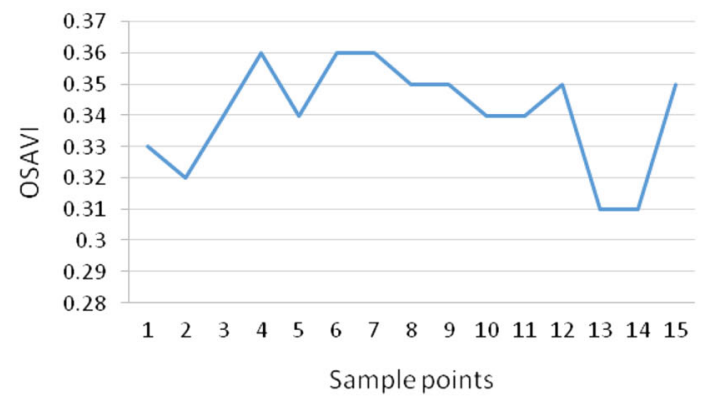

(g)

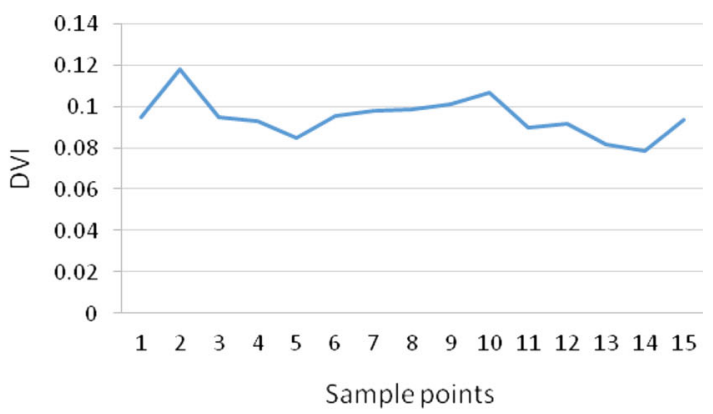

(b)

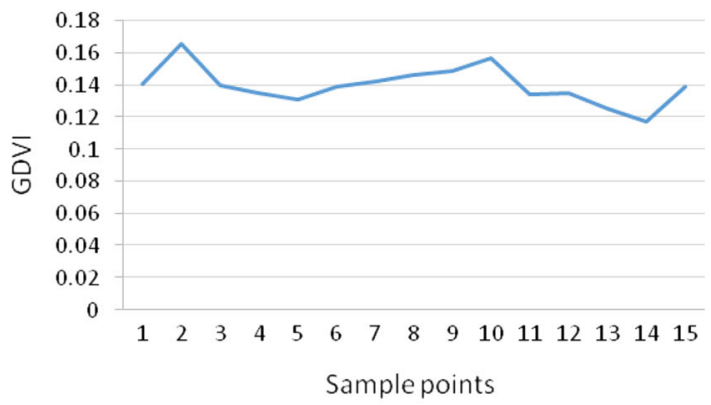

(d)

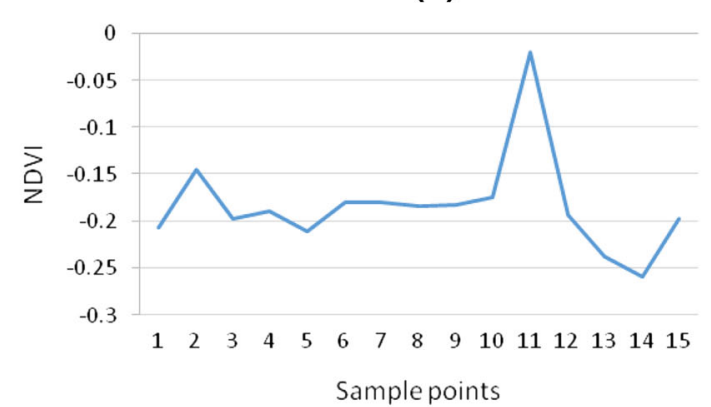

(f)

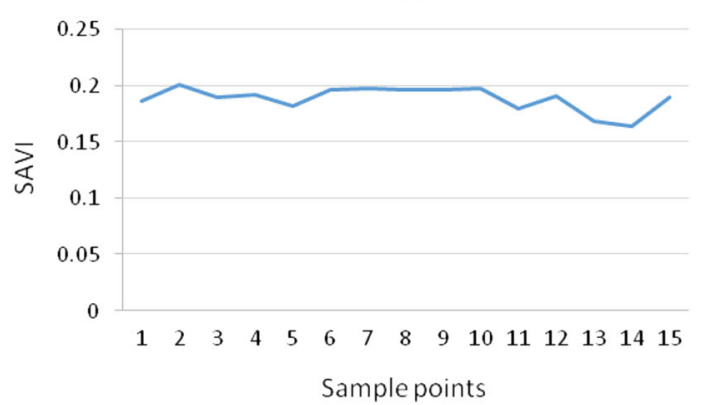

(h)

Fig. 4 The comparison of vegetation indices in the study area and sample points plotted versus. Change was same for SAVI, EVI, GDVI and DVI. a VARI, b DVI, c EVI, d GDVI, e IPVI, f NDVI, g OSAVI, h SAVI

According to Fig. 4 determined that cannot used IPVI and OSAVI for determination of soil salinity. DVI and SAVI close to 0.1 and 0.2 is represent soil salinity respectively. Also soil salinity have EVI and GDVI close to 0.14 . Finally VARI and NDVI have value of lower that 0 in soil salinity. For in the study area, EVI and SAVI are the best salinity indicator. The SAVI and EVI were developed as a modification of the Normalized Difference Vegetation Index to correct for the influence of soil brightness when vegetative cover is low (Senseman et al. 1996; Holben and Justice 1981; Matsushita et al. 2007). In fact for determination of vegetation index and relationship between salinity soil and vegetation index use from remote sensing science. Remote sensing is the advanced tool for surveying. 
It provides the synoptic view of the area. Remote sensing satellites provide data with different spatial, spectral, radiometric and temporal resolutions. The comparison of vegetation indices show that change values were same for SAVI, EVI, GDVI and DVI in salt dome. Finally the results show that EVI, GDVI, OSAVI and SAVI are suitable for prediction and modeling of salt dome in the study area. So recommended that used EVI, GDVI, OSAVI and SAVI for modeling and prediction of salt land.

\section{Conclusion}

As the rapid access to detailed information about the vegetation, through conventional methods is very costly and difficult, use of remote sensing techniques in the study of vegetation has resulted in low volume have access to a host of information with high accuracy. In the study area relationship between indices VARI, DVI, EVI, GDVI, NDVI, OSAVI, SAVI and IPVI and soil salinity were determined. The results show that cannot used IPVI and OSAVI for determination of soil salinity. VARI and NDVI have value of lower that 0 in soil salinity. DVI and SAVI close to 0.1 and 0.2 is represent soil salinity respectively. Also soil salinity have EVI and GDVI close to 0.14 .

\section{References}

Abdollah Zadeh M, Nasiri MB (2008) Determine the acreage of potatoes in the city Borojen using time series images IRSP6. In: Geomatic conference. National Cartographic Organization, Tehran (In Persian)

Allbed A, Kumar L, Aldakheel YY (2014) Assessing soil salinity using soil salinity and vegetation indices derived from IKONOS high-spatial resolution imageries: applications in a date palm dominated region. Geoderma 230-231:1-8

Arzani H, Noori S, Kaboli SH, Moradi HR, Ghelichnia H (2009) Determination of suitable indices for vegetation cover assessment in summer rangelands in south of Mazandaran. J Iran Nat Res 61(4):997-1016 (In Persian)

Baihua F, Burgher I (2015) Riparian vegetation NDVI dynamics and its relationship with climate, surface water and groundwater. J Arid Environ 113:59-68

Bannari A, Staenz K, Haboudane D, Khurshid KS (2006) Sensitivity analysis of chlorophyll indices to soil optical proprieties using ground-reflectance data. Geoscience and Remote Sensing Symposium, 2006. IGARSS 2006. International conference on IEEE

Bao Y, Gao W, Gao Z (2009) Estimation of winter wheat biomass based on remotesensing data at various spatial and spectral resolutions. Front Earth Sci China 3(1):118-128

Ben-Dor E, Irons JR, Epema GF (1999) Soil reflectance. In: Rencz AN (ed) Remote sensing for the earth sciences: manual of remote sensing. Wiley, New York, pp 111-118

Crippen R (1990) Calculating the vegetation index faster. Remote Sens Environ 34:71-73

Fu Y, Yang G, Wang J, Song X, Feng H (2014) Winter wheat biomass estimation based on spectral indices, band depth analysis and partial least squares regression using hyperspectral measurements. Comput Electron Agric 100:51-59

Ghanghermeh AA, Roshan G, Shahkooeei E (2015) Evaluation of the effect of Siberia's high pressure extension on daily minimum temperature changes in Iran. Model Earth Syst Environ $1(3): 1-15$

Gitelson A et al (2002) Vegetation and soil lines in visible spectral space: a concept and technique for remote estimation of vegetation fraction. Int J Remote Sens 23:2537-2562

Gnyp ML, Bareth G, Li F, Lenze-Wiedemann VIS, Koppe W, Miao Y, Henning S, Jia L, Laudien R, Chen X, Zhang F (2014) Development and implementation of a multiscale biomass modelusing hyperspectral vegetation indices for winter wheat in the North China Plain. Int J Appl Earth Obs Geoinform 33:232-242

Holben BN, Justice CO (1981) An examination of spectral band ratioing to reduce the topographic effect on remotely sensed data. Int J Remote Sens 2:115-133

Huete A (1988) A soil-adjusted vegetation index (SAVI). Remote Sens Environ 25:295-309

Huete A et al (2002) Overview of the radiometric and biophysical performance of the modis vegetation indices. Remote Sens Environ 83:195-213

Ji L, Wylie BK, Nossov DR, Peterson B, Waldrop MP, McFarland JW, Rover J, Hollingsworth TN (2012) Estimating aboveground biomass in interior Alaska with Landsat data and field measurements. Int J Appl Earth Obs 18:451-461

Koppe W, Gnyp ML, Hennig SD, Li F, Miao Y, Jia L, Bareth G (2012) Multi-temporal hyperspectral and radar remote sensing for estimating winter wheatbiomass in the North China Plain. Photogramm Fernerkund Geoinform 3:281-298. doi:10.1127/ 1432-8364/2012/0117

Li W, Saphores JM, Gillesspie TW (2015) A comparison of the economic benefits of urban green spaces estimated with NDVI and with high-resolution land cover data. Landsc Urban Plan 133:105-117

Matsushita B, Yang W, Chen J, Onda Y, Qiu G (2007) Sensitivity of the enhanced vegetation index (EVI) and normalized difference vegetation index (NDVI) to topographic effects: a case study in high-density cypress forest. Sensors 2007(7):2636-2651

Metternicht GI, Zinck JA (2003) Remote sensing of soil salinity: potentials and constraints. Remote Sens Environ 85:1-20

Mougenot B, Pouget M, Epema G (1993) Remote sensing of salt affected soils. Remote Sens Rev 7:241-259

Prost GL (2013) Remote sensing for geoscientists: image analysis and integration, 3rd edn. CRC Press, Azar (22, 1392 AP-Science702 pages)

Ren J, Chen Z, Zhou Q, Tang H (2008) Regional yield estimation for winter wheatwith MODIS-NDVI data in Shandong, China. Int J Appl Earth Obs Geoinform 10(4):403-413

Ren H, Zhou G, Zhang X (2011) Estimation of green aboveground biomass of desert steppe in Inner Mongolia based on red-edge reflectance curve area method. Biosyst Eng 109(4):385-395

Rondeaux G, Steven M, Baret F (1996) Optimization of soil-adjusted vegetation indices. Remote Sens Environ 55:95-107

Rouse J, Haas R, Schell J, Deering D (1973) Monitoring vegetation systems in the great plains with ERTS. In: Freden SC, Mercanti EP, Becker MA (eds) Third Earth Resources Technology Satellite-1 Symposium- Volume I: Technical Presentations. NASASP-351. NASA, Washington, DC, p 309

Senseman GM, Bagley CF, Tweddale SA (1996) Correlation of rangeland cover measures to satellite-imagery-derived vegetation indices. Geocarto Int 11(3):29-38

Seyhan I (2004) RS \& GIS (remote sensing \& geographical information systems), p 4. http://www.mta.gov.tr/RSC_WEB/ rsgis.html.soils. Accessed 5 Sept 2014 
Sripada R et al (2006) Aerial color infrared photography for determining early in-season nitrogen requirements in corn. Agron J 98:968-977

Tillack A, Clasen A, Kleinschmit B, Forster M (2014) Estimation of the seasonal leaf area index in an alluvial forest using highresolution satellite-based vegetation indices. Remote Sens Environ $141: 52-63$

Tucker C (1979) Red and photographic infrared linear combinations for monitoring vegetation. Remote Sens Environ 8:127-150
Yospin GI, Wood SW, Holz A, Bowman DMJS, Keane RE, Whitlock C (2015) Modeling vegetation mosaics in sub-alpine Tasmania under various fire regimes. Model Earth Syst Environ 1:16

Zhang T-T, Sheng-Lan Zeng Yu, Gao Z-TO, Li B, Fang C-M, Zhao B (2011) Using hyperspectral vegetation indices as a proxy to monitor soil salinity. Ecol Ind 11(2011):1552-1562 